\title{
Ejection and filling rates assessed from cardiac magnetic resonance imaging: possible indices of Degenerative Mitral Valve Regurgitation
}

\author{
Stephanie Marchesseau ${ }^{*}$, Jamie X Ho ${ }^{1}$, John J Totman ${ }^{1}$, Lieng H Ling ${ }^{2}$ \\ From 19th Annual SCMR Scientific Sessions \\ Los Angeles, CA, USA. 27-30 January 2016
}

\begin{abstract}
Background
Degenerative Mitral Valve Regurgitation (DMR) is a severe form of mitral valve disease for which the survival rate is poor if left untreated. Defining the optimal timing for surgery is challenging in spite of advances in diagnostic imaging. No sensitive measure of left ventricular dysfunction from CMR have yet been reported since the ejection fraction (EF) is usually preserved in DMR patients. However, to assess LV function, standard analysis of the Cine images only focuses on two timepoints of the cardiac cycle (end-diastole and endsystole), discarding more than $80 \%$ of the available data. Available cardiac analysis software now allows the analysis of the entire cardiac cycle in a reasonable time, leading therefore to a full LV volume curve over time. The aim of this study is to assess the sensitivity of two indices extracted from the LV volume curve: the peak ejection rate and the peak filling rate.
\end{abstract}

\section{Methods}

30 patients with clinically identified DMR disease (22 males, mean age 52 range $=26-76)$ were recruited as well as 10 controls without known heart disease (8 males, mean age 50 range $=32-65)$. Both groups were scanned on a Siemens Trio 3T MRI. In addition to the localizer, breath-hold CINE steady state free precession (SSFP) short axis sequences were acquired (slice thickness $8 \mathrm{~mm}$ with $20 \%$ gap). Global LV function was quantified blindly using Segment v1.9 R3556 (http://segment.heiberg.se) by 3 trained analysts. Several indices were extracted from the full LV volume curve: the ejection fraction, the maximum and minimum amplitude of the flow (derivative of

${ }^{1}$ CIRC, Singapore, Singapore

Full list of author information is available at the end of the article the volume with respect to time) also referred to as the peak ejection rate (during systole) $|\mathrm{min}(\mathrm{dV} / \mathrm{dt})|$ and peak filling rate (during diastole) $|\max (\mathrm{dV} / \mathrm{dt})|$. Statistical 2 -sample $\mathrm{t}$-test was performed on these 3 indices to measure their sensitivity between the patient group and the control group.

\section{Results}

As shown in Figure 1, the ejection fraction shows no significant difference between patient and control groups. However, as already reported in previous studies, patients with DMR present a higher peak ejection rate $(|\min (\mathrm{dV} / \mathrm{dt})|=0.56(\operatorname{std} 0.14)$ for patients compared to $|\min (\mathrm{dV} / \mathrm{dt})|=0.45$ (std 0.14) for controls, $\mathrm{p}$-value $=0.03)$. In addition, in our study, the patient group demonstrates a significantly higher peak filling rate $(|\max (\mathrm{dV} / \mathrm{dt})|=0.52($ std 0.13$)$ compared to $\mid \max$ $(\mathrm{dV} / \mathrm{dt}) \mid=0.35$ (std 0.10) for controls, p-value $<0.001)$.

\section{Conclusions}

This study confirms the physiological understanding of DMR. The LV empties rapidly preferably into the low impedance left atrium rather than the high pressure aorta. The ejection fraction being preserved, the LV relaxation must also be faster. In addition, this study shows that two indices currently not measured in CMR could be predictors for degenerative mitral valve regurgitation severity. With now available analysis software, the peak filling rate and the peak ejection rate could easily be measured in a routine clinical environment.

\section{Authors' details}

${ }^{1}$ CIRC, Singapore, Singapore. ${ }^{2}$ Cardiac Department, National University of Singapore, Singapore, Singapore. 


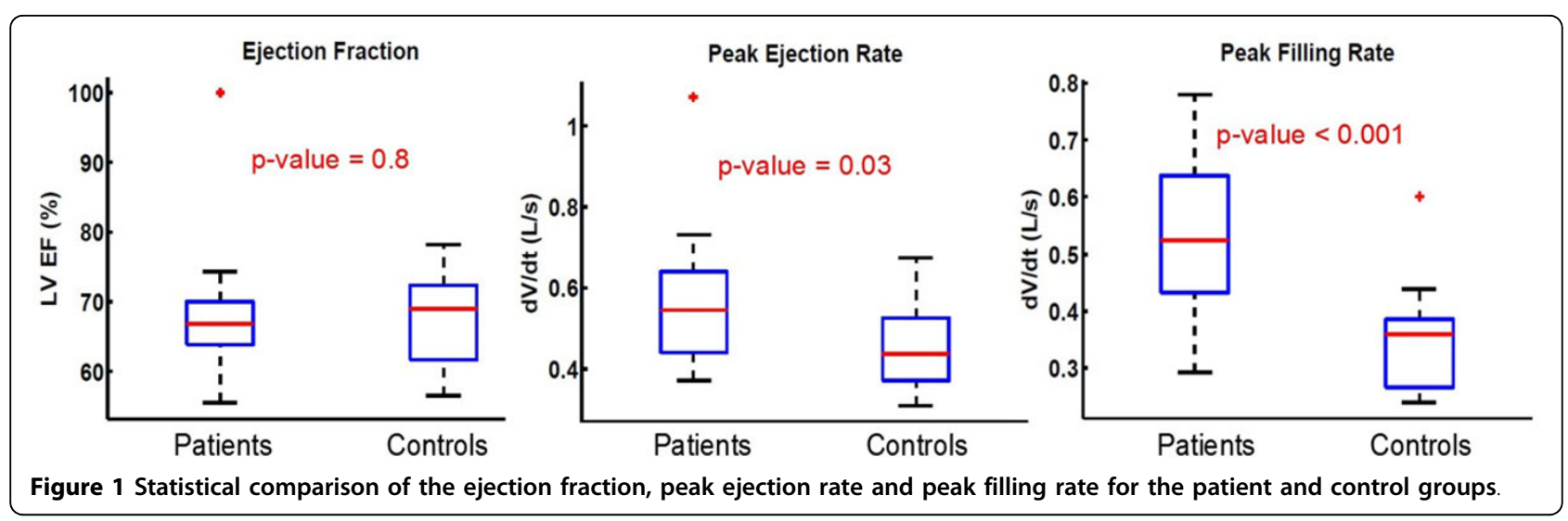

Published: 27 January 2016

doi:10.1186/1532-429X-18-S1-P347

Cite this article as: Marchesseau et al:: Ejection and filling rates assessed

from cardiac magnetic resonance imaging: possible indices of

Degenerative Mitral Valve Regurgitation. Journal of Cardiovascular

Magnetic Resonance 2016 18(Suppl 1):P347.

Submit your next manuscript to BioMed Central and take full advantage of:

- Convenient online submission

- Thorough peer review

- No space constraints or color figure charges

- Immediate publication on acceptance

- Inclusion in PubMed, CAS, Scopus and Google Scholar

- Research which is freely available for redistribution

Submit your manuscript at www.biomedcentral.com/submit 